\title{
Notas acerca de la significación en Platón y en Aristóteles
}

\author{
Notes on significance in Plato and Aristotle
}

\author{
Por: Eduardo Sinnott ${ }^{*}$ \\ Universidad del Salvador. Buenos Aires, Argentina \\ Email: eduardosinnott@hotmail.com
}

Fecha de recepción: 01/01/2019

Fecha de aprobación: 30/01/2019

Resumen: Aristóteles heredó de Platón una visión de la significación lingüística en la que se distinguen las dos dimensiones que hoy comúnmente se reconocen ella, esto es, la del significado y la de la referencia. Pero la tradición interpretativa concerniente a la visión aristotélica de la significación ha puesto énfasis unilateral en las líneas iniciales del De interpretatione, donde aquella distinción no es evidente. Eso ha llevado a muchos autores a negar que haya en Aristóteles una visión cabal de la significación lingüística tal como hoy en general se la concibe. La consideración de otros lugares de la obra de Aristóteles muestra que no es así: Aristóteles reconoce, aparte de la referencialidad, dos niveles en el sentido de las unidades léxicas, a saber, el nivel del sentido denotativo y el del sentido gramatical. Por otra parte, en el marco de la visión aristotélica es posible localizar en el ámbito de la experiencia (empeiría), la raíz del saber acerca de la significación y la raíz de la competencia lingüística en general.

Palabras Claves: Platón - Aristóteles -lenguaje - significación lingüística.

Abstract: Aristotle's view on linguistic significance, which he inherited from Plato, implies the two-dimensional distinction commonly recognized nowadays in this field: meaning and reference. However, the exegetical tradition on Aristotle's view on

\footnotetext{
* Doctor en Filosofía por la Universidad de Münster (Alemania). Profesor Emérito de la Universidad del Salvador (Argentina).
} 
significance unilaterally points out the opening lines from De interpretatione, where such distinction is not obvious.

For this reason, many authors have dennied that Aristotle provides a full view on linguistic significance as conceived nowadays. Nevertheless, examination of other passages in the Aristotelian corpus shows that this appraisal is wrong: Aristotle acknowledges, in addition to the referential aspect, two lexical unities meaning levels, -namely dennotative and grammatical. In addition, according to the Aristotelian view, it is possible to place the core of both knowledge about significance and linguistic competency in the sphere of experience (empeiría).

Key words: Plato - Aristotle - language - linguistic significance

\section{Cómo citar este artículo:}

APA: Sinnott, E. (2019). Notas acerca de la significación en Platón y en Aristóteles. Nuevo Itinerario, 14 (1), 304-329. Recuperado de: (agregar dirección web)

Para determinar la visión de la significación lingüística en Aristóteles la tradición interpretativa se ha centrado preferentemente en el esquema del proceso de la significación que se deduce de las líneas iniciales del De interpretatione (De int i 16a49). La preferencia por esas líneas ha sido tan insistente que hizo de ellas "el texto más influyente de la historia de la semántica" (Kretzmann, 1974, p. 3). La expuesta en esas líneas no es, sin embargo, la única visión de la significación presente en el corpus aristotélico, sino que en otros lugares de él se registra otra visión, insinuada ya en las líneas que completan el propio capítulo i del De int (16a10-19), y expresada con más claridad en otros lugares de la obra de Aristóteles que se han de considerar más abajo. Esta segunda visión resulta más definida e inteligible que la primera, al menos si para su apreciación se toman como punto de referencia las formas de ver modernas acerca de la significación lingüística ${ }^{1}$, las cuales (hechos a un lado los muchísimos matices

${ }^{1}$ Como parece forzoso en un trabajo de interpretación, el cual requiere comúnmente un punto de referencia. Preferimos hablar de "noción" o de "visión" de la significación en Aristóteles antes que de una "teoría" de ella, pues, al menos a nuestro modo de ver, no se da en su obra una cosa que pudiera 
diferenciales de cada uno de los enfoques teóricos particulares) coinciden en reconocer en ella dos dimensiones fundamentales, a saber, la del sentido (o el significado), por un lado, y la referencia (o la denotación) por el otro, la primera de las cuales (dicho en forma sintética) corresponde al contenido del que el signo lingüístico es portador, y la otra, a la relación del signo con las cosas ${ }^{2}$. Esa distinción se registra por primera vez en el Sofista platónico, diálogo del que se ha dicho, no sin razón, que es el verdadero texto fundador de la filosofía del lenguaje ${ }^{3}$. La distinción está también en Aristóteles, y ello sin duda como parte del legado conceptual que recibió de su maestro, sólo que, como se verá abajo, el Filósofo la presenta de manera más bien operativa, y, como hemos dicho ya, no en el lugar que la tradición ha privilegiado.

\section{Platón}

Como se ha observado muchas veces, la reflexión platónica acerca del lenguaje estuvo movida por la voluntad de determinar la relación del lenguaje con la verdad, lo cual suponía, como condición, aclarar primero en forma general la relación del lenguaje con el pensamiento y con las cosas. Se ha señalado asimismo que en ello Platón avanzó lentamente y en una secuencia de tres textos, a saber, el Cratilo (Cra.), el Teéteto (Tht.) y el Sofista (Soph.), y a razón de un diálogo para cada uno de los pasos $^{4}$. Así vistas las cosas, el Cra., antes que encerrar, como se suele decir a veces, la teoría platónica del lenguaje, resulta ser, más bien, sólo el punto de partida o la

definirse o caracterizarse de ese modo al menos en forma rigurosa, ni pareciera que pudiera haber un lugar definido para ella en el marco sistemático de su filosofía. Creemos que tampoco cabría esperar que hubiese en él una teoría de las características que reclama, de manera más bien anacrónica, Irwin (1982, pp. 242-243).

${ }^{2}$ Formulada con ese grado de generalidad, la distinción señalada es común a la semántica lingüística moderna y a la llamada a veces "semántica de los lógicos". En otros puntos, esos dos enfoques no coinciden; así, la semántica lingüística no solamente atiende a contenidos denotativos, sino también a contenidos gramaticales, como es el caso de la semántica de Aristóteles (cf. infra 3.3). Es sabido que entre los lógicos no hay unanimidad terminológica en relación con aquellas dos nociones; la terminología que se emplea las más de las veces es, respectivamente, la siguiente: Sinn y Bedeutung (Frege), Intension y Extension (Carnap), y meaning y reference (Quine).

${ }^{3}$ Cf. Tilman Borsche en: Schmitter (1991, l, pp. 140-169).

4 Cf. Steintahl (1969, p. 139): “Plato schritt langsam vor: jeder Schritt, ein Dialog". El Tht. y el Soph. están estrechamente vinculados entre sí (y con el Parménides) tanto desde el punto de vista temático cuanto desde el punto de vista dramático, puesto que en la ficción del diálogo el segundo es continuación del primero. Cf. Wyler (1965, pp. 20-25). 
primera etapa de un camino que conduce al Soph. En el primer momento de ese itinerario, representado, pues, por el Cra., se registra una visión nominativista de la significación y de la verdad, y en la última, esto es, en el Sofista, una visión proposicional de la verdad, que se expresa en una teoría del enunciado (lógos) e incluye una distinción nítida entre el sentido y la referencia. Platón comprueba, por tanto, que la forma lingüística pertinente en relación con la verdad y la falsedad no son ni el sonido aislado ni la palabra aislada (posibilidades examinadas en el Cra.), sino el enunciado, el cual se compone, en su forma mínima, de un “ónoma (nombre; sujeto)" y un "rhêma (verbo; predicado)". Al darse ese paso de la palabra o el nombre (ónoma) al enunciado (lógos), se hace definitivamente a un lado el problema de la "corrección (orthótes)", natural o instituida, de las palabras que se había planteado el punto de partida, y se comprueba que la unidad lingüística que mantiene con las cosas una relación de referencialidad es el enunciado, y que es en tal relación donde estriban la verdad y la falsedad. En el momento intermedio, es decir, en el Tht., se expone el decisivo descubrimiento ${ }^{5}$ del carácter articulado del lenguaje, esto es, que la estructura de la expresión lingüística consiste en una secuencia de niveles de integración, en cada uno de los cuales se dan unidades específicas, compuestas en cada caso por unidades del nivel precedente pero irreductibles a ellas. El nivel básico es el de los "elementos (stoikheîa)" fónicos, al que le siguen el nivel de la sílaba, el nivel de los nombres y el nivel del enunciado. Las unidades fónicas y silábicas no son vehículo de contenidos (son ásema); por tanto, sólo los nombres y los enunciados están asociados con contenidos ${ }^{6}$. El papel de las unidades del nivel superior es, se dice allí,

\footnotetext{
${ }^{5} \mathrm{O}$, acaso mejor, la consideración, en un registro filosófico, de un descubrimiento al que la práctica de la enseñanza de la lectura y la escritura había llevado a los grammatikoí. Cf. Sinnott (2017). El lugar en que se expresa con más claridad la estructura a que se hace referencia arriba a continuación es el capítulo xx de la Poética.

${ }^{6}$ La comprobación contradice uno de los supuestos de las etimologías del Cra., y es uno de los factores que favorecen la visión convencionalista. Cf. Sinnott (2004).
} 
Notas acerca de la significación en Platón y en Aristóteles

hacer manifiesto el pensamiento (diánoia) de uno por medio de la voz, en verbos y en nombres, como en un espejo o en el agua, estampando la opinión (dóxa) en la corriente bucal (Tht. 206d) ${ }^{7}$.

Pues bien, las expresiones que contienen un matiz o un componente icónico ("espejo", "agua", "estampar") ${ }^{8}$ no parecen conllevar las connotaciones negativas que la noción de imagen en general suele tener en Platón ni las implicancias que la iconicidad o las relaciones miméticas tienen en los lugares del Cra. en los que se busca en relaciones de esa naturaleza la clave para explicar la significación lingüística. Antes bien, las expresiones del Tht. recién citadas parecen ser sólo expresiones figuradas que suplen la falta de un recurso conceptual apto para expresar o para aclarar la relación que existe entre el pensamiento y el lenguaje, la cual queda indeterminada: a partir de las líneas citadas el lector no sabe positivamente si en efecto el pensamiento, que parece ser una cosa diversa del lenguaje, pertenece primariamente a un dominio extralingüístico o prelingüístico, ni, si es así, de qué modo asume a continuación una configuración lingüística, esto es, cómo se reviste de lingüisticidad al "reflejarse" en lenguaje. A primera vista al menos, se da, pues, aunque en otro marco o en otro sentido, la misma disociación entre el pensamiento y el lenguaje que se registra en el Cra.

La idea, implicada en la de los niveles de articulación de la expresión lingüística expuesta en el Tht., según la cual los componentes del enunciado (lógos), esto es, los nombres (onómata) y los verbos (rhémata), no están meramente yuxtapuestos el uno al otro, sino combinados entre sí en un entrelazamiento (symploké) en virtud del cual el enunciado se constituye como unidad de una naturaleza específica, irreductible a la de aquellas unidades, lleva a la comprobación de que entre el nivel de las unidades léxicas y el de las unidades discursivas se da una diferencia no sólo desde el punto de vista formal o estructural, sino también, y en correspondencia con ella, una diferencia

\footnotetext{
${ }^{7}$ En todos los casos, las traducciones de los textos, tanto platónicos como de Aristóteles, son de mi autoría.

${ }^{8}$ También en una alusión a esa definición que se lee en Tht. $208 c$ se expresa la idea de una relación especular entre pensamiento y sonido: "como una imagen del pensamiento en la voz (dianoías en phōnêi hốsper eídōlon)".
} 
desde el punto de vista semántico, que Platón expresa como diferencia entre el "onomázein (nombrar)" y el "légein (decir)", y que no es otra cosa que la diferencia entre el sentido (que se da en la palabra aislada) y la referencia (que se da en el enunciado). Con el enunciado se inaugura, por tanto, una modalidad de la significación específica, a saber, la remisión a una cosa o a un estado de cosas extralingüístico, que no se puede confundir con el solo "nombrar" las cosas. El enunciado las pone de manifiesto, esto es,

no solamente nombra (onomázei), sino que completa una cosa (ti peraínei) al combinar los verbos con los nombres. Por eso dijimos que [el enunciado: (lógos)] 'dice [légein]', y no sólo que nombra (onomázei), y a ese entrelazamiento (plégma) le dimos el nombre de 'enunciado (lógos)' (Soph. 262d).

Como se ha señalado, esta distinción hace que ya no se busque la verdad en el nivel de los nombres, y ello en razón de que, como se ve ahora, la verdad y la falsedad no son propiedades de las unidades léxicas, sino de las unidades del nivel discursivo, es decir, del enunciado, y ello, a su vez, porque sólo el enunciado es "acerca de algo (perì tinós; tinós)", es decir, sólo el enunciado tiene un referente extralingüístico. En efecto, el enunciado es verdadero o falso según diga "las cosas [= los referentes] que son como son" o diga "cosas distintas de las que son" o "las cosas que no son como si fueran" (Soph. 263c). Ahora bien, la verdad y la falsedad que se dan en el enunciado se corresponden con la verdad y la falsedad que se dan en el pensamiento (diánoia) del hablante que formula el enunciado. Pues bien, en el Sofista no se da ya la ambigüedad o la indeterminación que se ha visto en el Tht. en lo que concierne a la relación entre pensamiento y lenguaje, a la que, como se ha visto, en ese diálogo se hacía referencia metafóricamente mediante la noción de imagen o de reflejo. Ahora, en el Soph., no se supone que el pensamiento sea primariamente de naturaleza no lingüística y asuma esa naturaleza al "reflejarse" en el lenguaje, sino que se concibe el pensamiento como lenguaje o como originariamente estructurado en forma lingüística:

pensamiento (diánoia) y enunciado (lógos) son lo mismo (tautón), salvo que lo que llamamos 'pensamiento' es el diálogo interior y sin voz del alma consigo misma (ho mèn entós tês psykhês pròs autèn diálogos áneu phōnês gignómenos). [...] La 
Notas acerca de la significación en Platón y en Aristóteles

corriente que sale de aquélla a través de la boca acompañada de sonido (tò dè g'ekeínēs rheûma dià toû stomátos iòn metà phthóggou) ha sido llamada [por nosotros] "enunciado" (Soph 263b). ${ }^{9}$

No hay, pues, distancia o heterogeneidad entre el pensamiento y el lenguaje, y así como el lenguaje no es concebible sino en el marco de un diálogo, el propio pensamiento (el pensamiento discursivo, la diánoia) reviste de por sí naturaleza dialógica. El lenguaje sin voz (áneu phōnês) en que consiste ese pensamiento pareciera ser el mismo lenguaje formado por vehículos fónicos, es decir, sensibles, sólo que ahora ese lenguaje, cuando es pensamiento, es imaginado, de manera tal que pensar no es sino decirse las cosas en silencio a sí mismo, y hablar es decirles a los otros aquello mismo, esto es, consiste en formular el decurso del diálogo interno esta vez por medio de los sonidos audibles, y no sólo imaginados o tácitos. Los contenidos lingüísticos no traducen (no "reflejan" de algún otro modo) contenidos "intelectuales" o "psicológicos" prelingüísticos o alingüísticos que precedan a esa traducción, en sonidos, sino que los contenidos son lingüísticos desde el inicio, y, en todo caso, es el acto de comprender esos contenidos lo que en todo caso reviste carácter "intelectual" o "psicológico".

\section{2. $\quad$ Aristóteles}

\section{a. De interpretatione i}

Como hemos señalado al comienzo, es posible hallar en Aristóteles una visión del signo y de la significación que en lo esencial coincide con la platónica recién examinada, y que conlleva básicamente las mismas implicancias que ella. No es ésa, empero, la visión que se registra en el ya mencionado locus classicus acerca de este tema, esto es, en las líneas iniciales del De int (i 16a3-9), que ahora es menester transcribir in extenso:

Las expresiones fónicas [tà en têi phōnêi] son símbolos [= signos convencionales] de las afecciones (pathémata) del alma, y las expresiones escritas [tà graphómena] [lo]

${ }^{9}$ Cf. Tht. $206 d$. 
son de las expresiones fónicas; y tal como las letras no son las mismas en todos [los hombres], tampoco las expresiones fónicas son las mismas en todos [los hombres]; pero las cosas de las que ésas [= las expresiones fónicas] son signos primariamente, [esto es], las afecciones [pathếmata] del alma, son ya las mismas en todos [los hombres], y las cosas [prágmata] ${ }^{10}$ de las que éstas [= los pathếmata] son símiles [homoiốmata], son las mismas [en todos los hombres]. Pero acerca de esos [temas] se ha tratado en los [libros] acerca del alma, pues corresponden a una investigación distinta (De int i 16a3-9).

Aristóteles sostiene, pues, que las expresiones escritas son símbolos (sýmbola), esto es, signos convencionales ${ }^{11}$, de las expresiones fónicas; que las expresiones fónicas son "primariamente (prótōs)" signos (sēmeîa) o símbolos de las "afecciones del alma (pathếmata tês psykhês)", y que las "afecciones del alma son "símiles (homó́iómata)" de las $\operatorname{cosas}^{12}$. Se suele representar todas esas relaciones por medio de un esquema triangular (el "triángulo semiótico"), cuyos vértices corresponden las "afecciones del alma", las "expresiones fónicas" y "las cosas". En ese esquema se ha visto un lejano esbozo del triángulo en que modernamente Frege resumió su modelo del signo y la significación ${ }^{13}$. Si a las instancias mencionadas se agregan las "expresiones escritas", se tienen entonces dos triángulos que comparten uno de los $\operatorname{lados}^{14}$.

A fin de apreciar los puntos de divergencia respecto de la visión platónica examinada arriba, nótese que las "afecciones del alma" ocupan aquí el lugar de los contenidos lingüísticos, en la medida en que son el correlato del signo (sēmeîon), el cual, por eso, en esta ocurrencia al menos, se debe entender que es el solo

\footnotetext{
10 "las cosas" traduce, pues, "tà prágmata", es decir, las cosas denotadas mediante un término que da a entender que se trata de las cosas reales tal como son de por sí al margen de lo que pensamos o decimos.

11 A juicio de Kretzmann (1974, p. 15), las expresiones fónicas son, en cambio, "signos naturales" o "síntomas" de las "impresiones mentales" del hablante. En Weidemann (1982, pp. 244-245) se halla una válida crítica de esa singular interpretación.

12 Sobre todo por su vaguedad o por su amplitud, las dos expresiones destacadas ("pathếmata tês psykhês" y "homoiốmata") han resultado (y resultan) particularmente problemáticas; de ahí que los mayores esfuerzos interpretativos en torno de este texto se hayan dirigido sobre todo a la aclaración de esas expresiones. Cf. Pépin (1985); Kretzmann (1974); Weidemann (1991); Polansky, R.; Kuczewski, M. (1990); Wheeler (1999).

${ }^{13}$ Frege (1975): cf. Weidemann (1991, p. 17).

${ }^{14}$ Cf. Lieb (1981, p. 149).
} 
significante, ya que el significado, que vienen a ser, pues las "afecciones del alma", no forma parte de él, es decir, el "significado" no es componente de la palabra misma, sino algo externo a ella. Además, a pesar de que el sentido preciso de la expresión "afecciones del alma" es enigmático en el presente contexto, de todos modos es claro, por un lado, que el giro remite a un fenómeno psicológico que se da en la subjetividad del hablante, $\mathrm{y}$, por otro, que, como lo indica nítidamente el término "homoiốmata (símiles)", ese fenómeno psicológico se liga con las cosas (esto es, sin duda, con las cosas que pueden funcionar como referentes particulares del vehículo sígnico) mediante una relación de índole icónica ${ }^{15}$. Dado que inmediatamente después de estas líneas (a saber, en De int 16a10) Aristóteles emplea el término "nóēma (pensamiento)" para referirse a lo mismo que aquí se caracteriza como "afecciones del alma", habría que suponer que, entonces, el fenómeno "psicológico" en cuestión es del orden del pensamiento, y que, por tanto, representaría un contenido intelectual no lingüístico ${ }^{16}$. No parece fácil armonizar o compaginar o equiparar ambas caracterizaciones de las "afecciones del alma", esto es, la que dice que esas afecciones son "símiles (homoiómata)" y la que dice que son "pensamientos (noémata)", porque la primera invita a ver en las "afecciones" no un fenómeno psicológico de índole intelectual, sino imaginativa ${ }^{17}$. Esto último sugiere que son la "figuración" que de un

\footnotetext{
${ }^{15}$ Se consideraría que esos "símiles" son un fenómeno del orden de la "representación (Vorstellung)" de Frege (1975, p. 12), pero no revista la índole individual o idiosincrásica de ésta, ya que, según se señala en ese lugar del De int, las "afecciones" son las mismas en todos los hombres.

${ }^{16}$ Esos contenidos intelectuales, como observa Hudry (2011, p. 257 y p. 270), resultan ser contenidos no convencionales (son los mismos en todos los hombres) que funcionan como contenidos lingüísticos de signos lingüísticos (convencionales, que no son los mismos en todos los hombres). Por tanto, el lenguaje convencional consiste en sonidos significativos cuyos significados lingüísticos son símbolos convencionales de pensamientos no lingüísticos "naturales" referentes a las cosas reales. No es fácil concebir de qué modo puede un acto de la imaginación como tal ser contenido de una expresión fónica, o en qué sentido pueden los sonidos ser "signos naturales de afecciones del alma" (Wheeler, 1999, p. 202 y p. 203). La dificultad resulta del hecho de que como contenido se postula un proceso psicológico de índole alingüística o prelingüística. La remisión al De anima con que se cierra el párrafo citado arriba no permite aclarar la cuestión, porque no parece posible identificar el lugar preciso de esa obra al que Aristóteles remite (si acaso piensa en algún lugar determinado).

${ }^{17}$ Las aclaraciones de este punto se han basado en suposiciones tales como la de que se trata de la relación de similitud que guardan con las cosas las imágenes (phantásmata) que, de acuerdo con De an III viii 432 a7-14, acompañan el pensamiento y le sirven a éste como una suerte de apoyo (cf. Kretzmann, 1974), o en la similitud o entre la forma o la especie (eîdos) como contenido del pensamiento y las cosas particulares que comparten esa forma (Polansky, 1990), etcétera. Todas esas respuestas suponen una cadena de elipsis demasiado extensa, $y$, a nuestro modo de ver, ninguna de ellas resulta verdaderamente clara y convincente. Por cierto, en el De an III iii se señala que entre el
} 
estado de cosas particular se da en el hablante antes del acto de habla, y que el hablante da a entender a un interlocutor, articulándola lingüísticamente, es decir, trasladándola a la esfera del lenguaje $y$, con ello, al terreno de lo comunicable, de manera tal que el contenido se vuelva accesible al otro. Si es así, entonces en el esquema aristotélico se plantea la misma problemática cuestión que se planteaba en el Tht. platónico, esto es, la de la relación entre un pensamiento no lingüístico y los contenidos lingüísticos, o de la traducción del primero a los segundos: cuestión que, como se ha visto supra, en ese diálogo Platón soslayaba recurriendo a una expresión figurada, a saber, la del símil del espejo o la imagen ${ }^{18}$. Ahora bien, en la medida en que en esta primera parte del capítulo i del De int no se reconoce una dimensión rigurosamente semántica, es decir, una dimensión de índole propiamente lingüística, diferenciada del nivel "psicológico" del pensamiento, entonces lo que en ellas se da a entender es, como se suele decir, una visión del significado de sesgo "psicológico", "mentalista" o "ideacionista"19. Aparte de eso, no se registra referencia alguna, al menos explícita o directa, a la distinción entre las dos dimensiones de la significación ${ }^{20}$.

pensamiento y la imaginación hay una colaboración estrecha, pero eso no permite hacer de ambas una facultad única; por el contrario, Aristóteles señala allí mismo de manera expresa y clara que son cosas distintas; cf. De an III iii 427b14-15. -- Weidemann (1988, p. 11) sugiere una interpretación distinta, que mitiga la tensión entre las dos determinaciones, a saber, que los "símiles (homoiómata)" no se deben entender en el sentido de imágenes o representaciones sensibles, sino que sería un modo de dar a entender que cuando hablamos hacemos que nuestro pensamiento se detenga en las cosas a que nos referimos, y ello en el sentido en que en De int 16b20-21 se dice que cuando se da una expresión lingüística "el hablante detiene su pensamiento y el oyente se aquieta (hístesi [...] ho légon tèn diánoian, kaì ho akoúsas herémesen)".

${ }^{18}$ Por cierto, también aquí, en el De int i, en la noción de "símiles (homoiómata)" está presente una idea de iconicidad, pero lo está a propósito de la relación entre el pensamiento y las cosas, y no a propósito de la relación entre el pensamiento y el lenguaje.

${ }^{19}$ Con lo que a veces se implica que su visión del significado es sencillamente errónea. Cf. Kretzmann (1973); Bolton (1976). En parte al menos a causa de la ya señalada centralidad que se le ha otorgado a De int i 16 a4-9, muchos autores de habla inglesa han propendido a entender que, en general, Aristóteles o no diferencia entre sentido y denotación o no reconoce una dimensión del sentido; cf. Hamlyn (1978); Bolton (1976); Irwin (1982); Polansky; Kuczewski, (1990); Wheeler (1999); y ello en contraste con autores de la tradición alemana que citamos más abajo.

${ }^{20}$ Las más de las veces se entiende que el adverbio "primariamente (prótōs 16a8)" implica tácitamente que, por tanto, "secundariamente" las expresiones fónicas son signos de las cosas. Únicamente en esa implicancia tácita se podría ver un correlato de la distinción entre la dimensión del significado (que sería vista como "primaria") y una dimensión de la referencia (que sería vista como "secundaria"). Si se lo acepta, entonces habrá que decir que la prioridad residiría en que el sentido es condición de la referencia. Kretzmann (1974, p. 5) rechaza la suposición que acabamos de resumir, y niega, por eso, que haya en Aristóteles siquiera el esbozo de una teoría general del significado. Se hallará una interpretación distinta en Pépin (1985, pp. 37-38). 
Notas acerca de la significación en Platón y en Aristóteles

Las líneas que completan el capítulo i del De int tienen una coloración distinta de la de las líneas precedentes, con las cuales se hallan en cierta tensión. Es menester citarlas también en su totalidad:

Tal como en el alma [en têi psykhêi] [se da] a veces un pensamiento [nóēma] sin que haya ni verdad ni falsedad, y a veces [un pensamiento] en el que necesariamente se da lo uno o lo otro, así ocurre también en el habla [en têi phōnêi], pues lo falso y lo verdadero se dan en la composición y la separación. Los nombres [onómata] y los verbos [rhếmata] de por sí se asemejan al pensamiento [noếmati] sin composición y separación --por ejemplo, "hombre" o "blanco"--, si no se agrega nada, pues [sin ningún agregado el pensamiento] no [es] aún ni verdadero ni falso. Es indicio de ello esto: que si bien "chivociervo [tragélaphos]" significa algo [semaínei <...> ti], no es ni verdadero ni falso si no se agrega que es o que no es, ya sea sin más o en un tiempo [verbal determinado] (De int i 16a10-19).

A nuestro modo de ver, en estas líneas se percibe al menos un eco de la distinción platónica entre la esfera del sentido y la de la referencia formulada en el Soph., y ello, en este lugar del De int, a propósito de los dos niveles, correlativos, del pensamiento (en têi psykhêi) y la expresión (en têi phonêi) a la vez. Es claro, por un lado, que lo que en uno y otro de estos dos niveles se da como unidad aislada ("hombre" o "blanco" en el nivel de la expresión, y los "pensamientos (noémata)" respectivos de esos significantes en el del pensamiento) son lo que en el Soph. las palabras aisladas, que expresan o tienen un sentido (esa forma de la significación era caracterizada en ese texto platónico un "onomázein"), y que, por otro lado, las expresiones que resultan de la reunión de un sujeto (ónoma) y un predicado (rhêma) esto es, el enunciado apofántico que afirma ("composición”) o niega ("separación"), y tiene, por tanto, valor de verdad- corresponden a las unidades del nivel del "decir (légein)" platónico, el cual, se decía en el Soph., siempre es "de algo (tinós)", es decir, siempre tiene un referente, y es verdadero o falso según lo que el enunciado declare acerca de ese referente. No hay en las líneas del De int recién transcriptas ninguna expresión que equivalga a (o que pueda ser considerada correlato explícito de) ese "de algo (tinós)"; la noción está, en todo caso, solamente como una implicancia, en la 
medida en que se habla de verdad y falsedad, que son propiedades del enunciado que derivan precisamente de la naturaleza de su relación con el referente. Si no se reúnen, pues, los componentes posibles de un enunciado, se está solamente en el nivel de la significación pura, y no hay referencialidad. Por cierto, cualquier otra palabra con valor denotativo distinta de "chivociervo (tragélaphos)" -por ejemplo, la antes aducida de "hombre"- podría haber sido igualmente apta para ilustrar el hecho que se quiere ilustrar, es decir, que existe en la lengua un nivel así; el que Aristóteles haya escogido "chivocierto (tragélaphos)" debe de responder a la intención de subrayar la diferencia entre el sentido y la referencia; esto es, hay sentido (la palabra "chivociervo" lo tiene) por más que no haya o no pueda haber ejemplo real de un chivociervo. El sobreentendido es, sin duda, ése: que para "chivociervo" no hay denotatum posible (ya sea porque a todos les consta que no existen chivociervos, ya sea porque no es posible una cosa que sea chivo y ciervo a la vez, ya sea por otra razón); y se lo dice por si acaso alguien pensase que el tenerlo es condición para que se dé la significación. Tampoco hay verdad o falsedad ni, por tanto, una relación referencial, si al nombre no se agrega un predicado con el que, como, según se ha visto, decía Platón en el Soph., "se complete una cosa (ti peraínei)", es decir, se forme la totalidad de un enunciado, y en él se implique, entonces sí, que, por ejemplo, el chivociervo existe o que no existe. Un punto de importancia de estas líneas es, por otro lado, que se diga que la palabra significa (ho tragélaphos semaínei ti); ${ }^{21}$ es, en cambio, el hablante el sujeto de la enunciación, esto es, el que formula el enunciado (lógos) y dice (légei) con él una verdad o una falsedad.

Hemos señalado arriba que entre esta segunda parte del capítulo y la primera se registra al menos una cierta tensión conceptual; precisemos que eso se da no sólo

\footnotetext{
${ }^{21}$ Aunque el artículo con que comúnmente se acompaña la palabra mencionada es el neutro ("to"), y no el artículo que corresponda al substantivo (que en este caso es el masculino), es claro que la palabra es mencionada (y no usada), y que funciona como sujeto gramatical del "sēmaínein (significar)". Este verbo tiene en Aristóteles un uso amplio, que abarca indistintamente las dos dimensiones de la significación, por lo que en muchas de sus ocurrencias no es fácil establecer, si no es por el contexto, cuál de esos dos valores es el que está en juego en cada caso si en efecto lo está uno de ellos específicamente. El punto ha sido suficientemente subrayado hace tiempo por Haller (1963). Este autor señala que en Aristóteles no hay distinción terminológica entre las nociones de sentido y de referencia, y no (como a veces parece que se le hace decir) que en Aristóteles no se las distinga. Cf. infra la nota 31.
} 
por el grado de nitidez con que en cada una de ellas está presente la distinción entre sentido y referencia ${ }^{22}$, sino también, y sobre todo, porque el contenido de un signo es visto en la primera parte como un fenómeno o acto psicológico de índole imaginativa o intelectual (o con una cara intelectual y otra imaginativa), pero en todo caso externo al signo, el cual, por tanto, queda reducido, como ya hemos dicho, al solo significante, mientras que en la segunda parte del capítulo el significado es un componente interno del signo, ya que es la palabra la que significa. Este contraste conlleva una diferencia en el modelo o esquema del proceso de significación supuesto por cada una de ellas: la primera parte del capítulo responde a un modelo triádico o triangular de ese proceso (del estilo de Frege o de Ogden y Richards), mientras que la segunda parte responde más bien a un modelo saussureano, en el que sólo se tiene el signo o el signo y la $\cos ^{23}$.

En realidad esa segunda forma de verse la significación coexiste con la primera en el propio texto del De int al menos embrionariamente en el uso del adjetivo "semantikós (significativo)", el cual recurre ubicuamente en ése y en otros textos de la obra de Aristóteles con el papel de modificador del "voz (phōné)" en el definiens de las categorías de unidades del nivel léxico y del nivel discursivo, cada una de las cuales es determinada como una especie del género "voz significativa (phōnè sēmantiké) ${ }^{24}$. Esas expresiones suponen sin duda el reconocimiento de que la significatividad es una propiedad interna de esas unidades: propiedad que la palabra tiene como tal, y que no depende, por tanto, de que un acto de pensamiento le confiera un contenido. Así que la palabra no es sólo el signifiant, como se deducía de la primera parte del capítulo, sino signifiant más signifié. Además, pareciera poderse hallar, fuera del De int, al

${ }^{22}$ En la primera lo está sólo como una implicancia probable; cf. supra la nota 22. La señalada tensión entre ambos segmentos del capítulo podría sumarse a otras razones que han sido aducidas en la tradición, para sugerir que corresponden a momentos distintos o aun a manos distintas. Por nuestra parte, no estamos en condiciones de fundamentar cabalmente una suposición en ese sentido, por más que impresione como probable.

${ }^{23}$ Lieb (1981) ha mostrado que el modelo de Ogden y Richards desciende del esquema que se deduce de la primera parte del De int $\mathrm{i}$, y lo llama "el modelo aristotélico del signo (das aristotelische Zeichenmodell)", caracterización que Weidemann (1991, p. 14) objeta, puesto que, como mostró en su momento Schmitter (1981, pp. 196-199), el modelo es, en todo caso, platónico, en la medida en que está ya esbozado en el Cratilo (434a-435e), con el matiz diferencial de que en Aristóteles el centro de gravedad está en el emisor, mientras que en Platón lo está en el receptor.

${ }^{24}$ El "ónoma (nombre)", por ejemplo, es definido como una "voz significativa (phōnē sēmantikē)"; Poet xx 1457a10-12, etcétera. 
menos un lugar en el que se registra una suerte de tránsito de la primera visión a ésta otra o de eslabón entre ambas ${ }^{25}$, a saber, una frase que se lee en el De anima y que declara que, como es significativa, la emisión de voz (en el lenguaje) tiene que estar acompañada de imaginación (o de una [forma de] de imaginación) ${ }^{26}$ : la frase incluye, pues, la expresión "significativa (semantiké)", que remite a la segunda visión, y coexiste con una referencia a la imaginación (phantasía), la cual remite, en cambio, a la visión primera. El sentido de la frase no es, a mi modo de ver, del todo evidente: si la emisión de voz es, como se dice allí, significativa (semantikós), lo es de por sí, esto es, no requiere, para serlo, de la imaginación como factor complementario, el cual sí sería indispensable en caso de que (como se ha visto en el texto de la primera parte de De int i), para formular un enunciado acerca de un estado de cosas empírico, el hablante debiera representarse primero ese estado de cosas en un acto del pensamiento que, como "símil (homoíoma)" imaginativo que sería al mismo tiempo, mantendría con ese estado de cosas una relación icónica, gracias a la cual la expresión adquiriría su semanticidad.

\section{b. Metafísica IV iv}

Pues bien, en otro lugar de la obra de Aristóteles, a saber, en el marco de la defensa del principio de contradicción expuesta en el capítulo iv del libro IV de la Metafísica (Met), apela el Filósofo a una noción de la significación que contrasta con la sugerida en la primera parte de De int $\mathrm{i}$, y que, como hemos anticipado, está en la línea de la visión platónica del Sofista, en la medida en que no se apela ya a nociones como la de "símiles (homoiómata)" o como la de un "pensamiento (prelingüístico)", y se da a

\footnotetext{
25 Sin implicar con la palabra "tránsito" una relación genética o diacrónica entre dos visiones (una más temprana o primera y otra posterior o "madura", etcétera). Las características del corpus aristotélico son tales que, como es sabido, las hipótesis de esa índole son extraordinariamente arriesgadas Se trata, en todo caso, de dos visiones diversas que, por así decir, coexisten en la sincronía del corpus, y de una tercera en la que se insinúa una transición teórica, en la medida en que reúne elementos de una y de otra visión.

${ }^{26}$ De an II viii 420b31-33: metà phantasías tinós: sēmantikòs gàr dē tis psóphos estìn hē phōné. En su comentario Hicks (1965, p. 109) señala que, en principio, la imaginación sería aquí indispensable para que el animal realice los movimientos necesarios para producir la voz, puesto que en De an III x y xi se le asigna a la imaginación un papel en el movimiento, pero como el propio Hicks parece implicar, eso no parece compaginarse del todo con el que la imaginación sea condición para que el sonido sea significativo.
} 
entender, en lugar de eso, una distinción entre la dimensión del significado y la de la referencia. El punto ha sido sugerido por Coseriu hace un cierto tiempo, y pasado por alto o interpretado prejuiciosamente por otros autores ${ }^{27}$.

En lo que se puede considerar la primera argumentación aristotélica en ese lugar, ${ }^{28}$ se toma como punto de partida el hecho de que cualquier unidad lingüística que formule un antagonista que negase la validez del principio de contradicción (por ejemplo, la palabra "hombre") ha de tener forzosamente un significado, puesto que las palabras significan ${ }^{29}$. La distinción entre significado y referencia, que desempeña un papel decisivo en la argumentación, está en las líneas que siguen, en las cuales Aristóteles se sitúa conscientemente en el plano metalingüístico, que es el relevante ahora $^{30}$ :

Además, si "hombre" significa una única cosa [semaínei hén], sea esa cosa "animal bípedo": llamo "significar una única cosa" lo siguiente: si "hombre" es eso [ = "si 'hombre' significa eso, es decir, si significa 'animal bípedo'”], toda vez que [se dé] una cosa [que] sea "hombre", eso ['animal bípedo'] será [para esa cosa] ser hombre (Met IV iv 1006a32-34). ${ }^{31}$

27 Coseriu (1979, p. 433) no hesita en afirmar que es en Met IV iv "donde Aristóteles define la significación por primera en la historia del pensamiento occidental (wo Aristoteles zum erstenmal in der Geschichte des abenländischen Denkens die Bedeutung definiert) "- apreciación en la que no se tiene en cuenta, sin embargo, que la distinción está ya en el Sofista. Un ejemplo de una interpretación distinta se halla en Irwin (1982).

${ }^{28}$ Met IV iv 1006a28-b11.

${ }^{29}$ En este contexto, para decir que la palabra tiene un significado se dice literalmente: "el nombre significa (sēmaínei tò ónoma)", Met IV iv 1006a28-31, frase en la que "ónoma" (como se ha visto arriba a propósito de "tragélaphos" en De int i) funciona como sujeto gramatical del verbo "significar (sēmaínein)". Por tanto, como en las expresiones del estilo de "voz significativa (phonè semantiké)" ya comentadas, también aquí se da a entender que son primariamente los "nombres", y no los hablantes, los que significan, en tanto que los hablantes son sujeto del "decir (légein)", esto es, del acto de habla. En este lugar de Met IV iv la significación se asocia, pues, a las palabras antes que a las intenciones significativas de los hablantes o a algún otro aspecto de la subjetividad de ellos. En esta segunda visión se reconoce, en efecto, la autonomía del lenguaje como espacio del sentido de por sí o como ámbito que puede ser concebido como tal con independencia de todo contexto comunicativo particular $y$, en general, con abstracción de todo lazo con el nivel pragmático.

${ }^{30}$ Se puede tomar como indicio complementario de que Aristóteles lo hace en forma consciente el hecho de que, a falta de comillas, emplee la sustantivación con "tó" ("tò ánthrōpos") para dar a entender que se trata de la mención de la palabra, esto es, que aquí el objeto que se considera es la palabra, y que la observación reviste, por tanto una índole metalingüística.

${ }^{31}$ La noción aristotélica de "significar una cosa (semaínein hén)" da a entender que el significante tiene un contenido unitario que recurre en cada una de sus aplicaciones; por oposición a la noción de 
Es claro, pues, por una parte, que la frase "animal bípedo" es una perífrasis que expresa el significado (la Bedeutung) de "hombre", y, por otra parte, que la relación de esa palabra con "una cosa (ti)" a la cual le es aplicada pertinentemente, esto es, la relación con éste o con aquel hombre particular, es la referencia (la Bezeichnung). Los niveles son, pues, nítidamente discernibles el uno del otro, aunque la diferencia no se exprese terminológicamente. En forma correlativa, en el marco de esta argumentación el pensamiento es visto, como en el Sofista platónico, en términos de una comunicación o un diálogo consigo mismo, esto es, como un pensamiento discursivo (diánoia) que es lenguaje o que ostenta ya originariamente una estructuración lingüística en la medida en que, por una parte, las condiciones del habla y las condiciones del pensamiento son las mismas, y que, por otra, en consonancia con eso se equipara el pensamiento con el habla consigo mismo y el habla con los otros como la explicitación del habla consigo mismo ${ }^{32}$.

\section{c. El significado gramatical}

En un segmento ulterior de Met IV iv (1006b11-33) emprende Aristóteles lo que se puede ver como un segundo momento de la argumentación en favor del principio de contradicción, en el cual se emplaza, como en el precedente, en el plano léxico, sólo que, mientras que en aquél se atendía al contenido denotativo, en éste se atiende a lo que la lingüística reconoce hoy como el nivel (semántico) de los contenidos gramaticales o categoriales, y que es, pues, junto con el denotativo, parte del

\footnotetext{
"significar de una cosa (kath'henós)", explicada más adelante en el mismo libro IV, conlleva la idea de que las entidades denotadas son autónomas desde el punto de vista ontológico. Consideramos ese punto en el apartado que sigue.

${ }^{32}$ Aristóteles explica que en refutaciones como la que se dispone a emprender, el punto de partida no consiste en solicitarle al adversario en el debate "que diga que una cosa es o que no es [... ], sino que signifique algo para sí mismo y para otro: pues eso [es] necesario si en efecto dice algo, pues si no [lo hiciese], un [hombre tal] no podría tener habla [lógos] ni consigo mismo ni con otro; < ... > al destruir [el oponente] el habla [lógon], acepta el habla [lógon]" (Met IV iv 1006a15-24). "[Y] si [el adversario] < ... > dijera que ["hombre"] significa infinitas cosas, [es] manifiesto que no podrá haber habla (lógos), pues no significar una sola cosa es no significar nada, y si los nombres no significan, queda destruido el diálogo de unos con otros, y, en verdad, también [el diálogo] consigo mismo, pues tampoco es posible pensar si no se piensa una sola cosa; y si es posible [pensar una cosa], [también] se le podrá poner a esa cosa [prâgma] un nombre único" (Met IV iv 1006b5-11).
} 
Notas acerca de la significación en Platón y en Aristóteles

contenido de las palabras ${ }^{33}$. Aristóteles denomina o define los dos modos de la significación que a su juicio se dan en el nivel gramatical de los contenidos semánticos "significar una cosa (hèn sèmaínein)" (giro que ya había sido mencionada en la cita precedente) y "significar (acerca) de una cosa (kath'henòs sēmaínein)".

La visión que aquí proponemos recoge una observación hecha hace muchísimo tiempo por $\mathrm{H}$. Bonitz ${ }^{34}$. Se la puede reformular en términos lingüísticos afirmando que en esta parte de la argumentación Aristóteles entiende que la índole substancial o accidental de lo denotado forma parte del significado gramatical de las palabras. Esta idea parece al menos echar luz sobre el sentido fundamental del desarrollo de la explicación, cuya concatenación con lo que precede queda, si no, más bien en la penumbra $^{35}$. Pues bien, en el segmento que se lee a continuación distingue Aristóteles las dos categorías semántico-funcionales mencionadas, que se corresponden al mismo

\footnotetext{
${ }^{33}$ Esto es, el significado asociado, por ejemplo, al significante "hombre" no sólo está constituido (en el nivel denotativo) por el contenido expresado en la perífrasis "animal bípedo", sino también (ahora en el nivel gramatical) por la condición de, diríamos hoy, substantivo, definido por los papeles que esa palabra puede desempeñar en el nivel sintáctico. El nivel gramatical del contenido de las palabras representa, pues, una suerte de eslabón o de transición hacia el nivel sintáctico, en la medida en que, como se acaba de señalar, los papeles sintácticos de las palabras están prefigurados en una parte del significado de ellas. La argumentación aristotélica culmina, en otro registro, en un tercer segmento, que va de 1007a20-1007b18, en el que, en contraste con los dos ahora considerados, que se emplazan en el plano léxico, se sitúa en el dominio de la predicación, esto es, ya en el nivel sintáctico.

${ }^{34}$ Cf. Bonitz (1848-1849, pp. 190-191): "Per sēmaínein hén ipsam notionem substantialem nominis alicuius significamus", esto es, agrega Bonitz, significamos la esencia; en cambio, con "kath' henós significamos "quaecumque de eoden subiecto praedicantur". Todo ello, como hemos dicho arriba, sin trascender el plano antepredicativo.

${ }^{35}$ La idea de que la unidad lingüística, que tiene determinado contenido denotativo, pueda conllevar al mismo tiempo, como parte de su significación, la determinación de la índole categorial de su contenido se halla también en la tesis, formulada en Cat iv, de acuerdo con la cual cada expresión que es "dicha sin combinación (symploké)", esto es, en forma aislada o fuera de la estructura de la predicación, denota o una substancia, o una cantidad o una cualidad, etcétera (Cat iv 1b25-27); esto es, la índole categorial es un contenido co-significado con el contenido denotativo particular del que es vehículo cada expresión que pueda desempeñar un papel en el nivel sintáctico de la predicación. La tesis supone, pues, una visión de la significación más amplia que la considerada hasta ahora, en la medida en que, como se ha visto, incluye el significado gramatical. La distinción de las categorías gramaticales y de las funciones sintácticas que ofrecen las teorizaciones de Platón y Aristóteles son, por cierto, muchísimo más sencillas que las modernas. Desde el Sofista platónico se distinguen nada más que los papeles de "sujeto" y de "predicado", que son vistos allí como correlatos de "nombre (ónoma)" y de "verbo (rhêma)". A esas dos categorías se les añaden en la Poética los nexos (sýndesmoi). La definición de las categorías de palabras en la Poética es, por otra parte, de índole semántica y combinatoria, pero en la teoría aristotélica de la predicación la definición de aquellas dos clases (la del "nombre" y la del "verbo") es funcional: en ella el papel y la condición de sujeto (hypokeímenon) está asociado a la noción de substancia, de la cual ése es rasgo propio y definitorio (tal como se lo dice tanto en la versión más temprana de la teoría de la substancia, expuesta en las Categorías, cuanto en su reformulación o rectificación o reelaboración en la Met, según se puede ver en los lugares respectivos).
} 
tiempo con dos especies de unidades léxicas y con los dos modos de la significación gramatical mencionados:

Sea, pues, como se dijo al principio [ = en 1006a21; 31], el nombre significante de algo, y significante de una sola cosa. [a] No es posible, entonces, que "ser hombre" signifique lo que "no ser hombre" si "hombre" no significa sólo de una sola cosa, sino también una sola cosa (pues no pretendemos que "significar una sola cosa" [sea lo mismo que] esto: "[significar] de una sola cosa"; [b] en efecto, en ese caso también "músico", "blanco" y "hombre" significarían una sola cosa, de modo que todas las cosas serán una sola, pues [serían] sinónimas) ${ }^{36}$; pero no es posible que lo mismo sea y no sea, salvo por homonimia, como si lo que nosotros llamamos "hombre", otros no [lo] llamaran" hombre" (Met IV iv 1006b11-20).

Dicho en términos que no son los que Aristóteles emplea, "significar una cosa" es, desde el punto de vista funcional, desempeñar o poder desempeñar una palabra el papel de sujeto o de predicado de una predicación; y "significar de una cosa" es desempeñar o poder desempeñar una palabra sólo el papel de predicado ${ }^{37}$. La distinción entre las dos modalidades se sitúa, como se ha dicho, en el plano del léxico $y$, por tanto, en el nivel antepredicativo: la forma de expresarse Aristóteles no debe inducir a error en este aspecto, porque si bien el circunstancial "katà tinós ([acerca] de una cosa)" se usa con mucha frecuencia en el nivel de la predicación, en este caso se trata, como se lo dice expresamente en el texto, de "significar (semaínein) de una cosa (katà tinós)", y no de "decir (de una cosa)", esto es, no se trata del "légein ti katà tinós", que es lo que típicamente expresa la predicación y que se sitúa, por tanto, ya

\footnotetext{
${ }^{36}$ Esto es, si se aboliera la distinción entre esos dos modos, las cosas se tornarían indistintas. Como se ve, la consecuencia está formulada en términos de que "todas las palabras pasarán a ser 'sinónimos", aunque, no "sinónimos" en sentido aristotélico (cf. Cat i 1a1-6), sino en sentido moderno; aristotélicamente se trataría más bien de un caso de "homonimia" (cf. Cat i 1a6-12), noción que se emplea a continuación (b19) en su sentido habitual.

${ }^{37}$ No parece que haya ninguna correspondencia precisa entre esas dos formas de significación y determinadas categorías gramaticales modernas. Se podría pensar que la distinción se corresponde con la distinción entre substantivo y adjetivo, pero no es así, pues, por una parte, en Aristóteles no existe una categoría particular que corresponda a lo que hoy se diferencia como "adjetivo", como se ve, por ejemplo, en la Poética xx, donde se implica que el adjetivo cae en la categoría general del "nombre (ónoma)"; por otra parte, en los ejemplos aristotélicos el papel de "predicado" no es desempeñado sólo por los "nombres" (substantivos o adjetivos), sino también por circunstanciales o por adverbios o giros adverbiales ("Sócrates es[tá] en la plaza"), con el valor categorial de lo que hoy desde el punto de vista gramatical se define como un "predicativo subjetivo obligatorio".
} 
Notas acerca de la significación en Platón y en Aristóteles

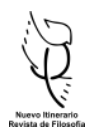

propiamente en el nivel sintáctico ${ }^{38}$. Por lo demás, pese a lo escuetísimo de la explicación de Aristóteles, es claro que el "significar una cosa" ostenta una prioridad respecto del "significar de una cosa", lo cual se corresponde, desde luego, con un punto central de la ontología de Aristóteles, esto es, la precedencia de la substancia respecto del accidente, la cual aparece, pues, reflejada o anticipada en el nivel semántico de las palabras. La prioridad de lo que "significa una cosa" respecto de lo que "significa de una cosa" deriva de que el papel de sujeto conlleva la idea de autonomía ontológica, y la de predicado (o modificador), la de dependencia ontológica. Así que, en definitiva, en la distinción semántica gramatical está anunciada o prefigurada y en cierta manera incluida como parte del contenido semánticofuncional de las palabras, la autonomía de los entes substanciales y la dependencia ontológica de las propiedades accidentales ${ }^{39}$.

\footnotetext{
${ }^{38}$ La distinción no separa las unidades léxicas en dos grupos, porque "hombre" (se dice en el texto) no significa sólo "una cosa (hén)", sino que significa también "de una sola cosa (kath'henós)", esto es (hay que entender) "hombre" puede desempeñar tanto el papel de sujeto ("El hombre es blanco") cuanto el de predicado ("Sócrates es hombre"); otros nombres, tales como "músico" o "blanco", en cambio, son predicados o no pueden funcionar sino como predicados ("Sócrates es músico"; "El hombre es blanco"), por más que (como se da a entender aquí y en muchos otros lugares de los escritos de Aristóteles) los nombres de esta clase pueden, sin embargo, desempeñar, de manera en cierto modo impropia desde el punto de vista lógico (aunque sea legítima desde el punto de vista gramatical), la función de sujeto ("[EI] blanco es músico"). Las denominaciones "accidentales" como "el blanco (ho leukós)", esto es, la substantivación de adjetivos por medio del artículo son, desde este punto de vista, falaces, en la medida en que sugieren que el contenido "blanco" es de la variedad de las unidades que sólo "significan una cosa (hén)", y que carece de la forma de "significar de otra cosa (kath'henós)", forma que es clara, en cambio, en la posición predicativa ("Sócrates es blanco").

${ }^{39}$ El punto es más nítido en la sección con que se cierra la argumentación considerada, en la cual, como hemos dicho ya, Aristóteles no se sitúa ya en el plano de la semántica, sino en el plano sintáctico. En esa sección (cf. en particular1007a21-b18 y 1007a31-33) se muestra que la negación del principio de contradicción conduciría a la supresión de la distinción entre los dos modos de la significación y a la imposibilidad consiguiente de la predicación; por esa vía se desembocaría forzosamente en un panaccidentalismo ( $y$ un escepticismo generalizado) en el que sólo sería posible predicar accidentes acerca de accidentes en una cadena infinita en la que los accidentes serían, pues, "predicados" unos de otros. Esa cadena no llegaría nunca a un sujeto que les confiriera base o unidad, así que se anularía la noción de substancia (ousía) y esencia (tò ti ên eînai), "porque lo que ['hombre'] significaba era una sola cosa, y esa cosa era la substancia [ousía] de algo", 1007a25-26). Con todo, tampoco una cosa así es posible, explica Aristóteles, porque entre los accidentes propiamente no puede haber ningún enlace predicativo: los accidentes no "se combinan [entre sí] (sympléketai)" para formar un enunciado en el que se exprese una predicación: la "combinación (symplokế)" supone el contraste ontológico entre un el sujeto y el predicado (cf. Cat ii 1a16; cf. Platón, Sofista 261c-264b); un accidente no puede ser accidente de un accidente (tò [...] symbebēkòs ou symbebēkóti symbebēkós, 1007b1-2), esto es, ni "músico" puede ser accidente de "blanco" ni "blanco" ser accidente de "músico".
} 
d. Acerca de la definición de las palabras

Se ha planteado la cuestión de si la perífrasis "animal bípedo" con que en Met IV iv se aclara el significado de "hombre" expresa un contenido de naturaleza semántica o, como piensa $\operatorname{Irwin}^{40}$, una realidad extralingüística, a saber, la esencia (el tò ti ên eînai) del hombre. De acuerdo con eso, habría que decir que la fórmula sería una definición de lo que la cosa es, no de lo que la palabra significa; ello al menos si uno se atiene a la distinción que Aristóteles establece en un conocido lugar de los Segundos Analíticos, donde a propósito de las definiciones se distingue en forma expresa el plano semántico del plano ontológico ${ }^{41}$, y se señala que, en la medida en que la llamada definición "nominal (onomatoeidés)" expresa, como se ha señalado, lo que el nombre significa (es lógos toû tí sēmaínei tò ónoma), no se la puede confundir con la definición de lo que la cosa es (lógos toû tí esti). Y bien, la manera en que se formula el contenido de "hombre" en el texto de Met IV iv citado arriba (y en otros lugares del mismo contexto), a saber, "que eso [= "animal bípedo] será [para esa cosa] ser hombre" ${ }^{\prime 2}$, sugiere, en efecto, que el alcance de la fórmula es ontológico y no semántico. Eso está en consonancia, además, con lo que Aristóteles más adelante declara en sentido general en el mismo libro IV, a saber, que el contenido del que la palabra es signo (sēmeîon) puede ser desplegado "en una definición" ${ }^{43}$, lo cual es dicho, por otra parte, en un contexto en el que "definición (horismós)" se entiende, en efecto, como expresión de la esencia (del tò tí ên eînai), y no de un contenido que indicase el valor lexicográfico de la palabra ${ }^{44}$. Así y todo, a nuestro modo de ver eso no implica que Aristóteles piense que al pasarse de lo uno a lo otro se desliza uno del dominio del lenguaje a un dominio ajeno o heterogéneo a él. La cercanía entre la "definición nominal" y la "definición real" es tan grande que no parece razonable

40 Irwin (1982, p. 246 y 248) niega por eso que en Aristóteles haya una teoría de la significación: el Filósofo no se ocuparía en rigor de cuestiones semánticas, sino de cuestiones epistemológicas u ontológicas, porque las palabras no denotan significados, sino esencias, y las esencias no son el significado o el sentido (meaning) de las palabras, sino propiedades de las cosas del mundo, así que pertenecen a la realidad no lingüística.

${ }^{41}$ Cf. en particular An Post II x 93b30-31.

${ }^{42}$ Met IV iv 1006a33, esto es, con "eînai" más dativo.

${ }^{43}$ Met IV vii 1012a23-24: "hó [...] lógos hoû tò ónoma sēmeîon horismòs éstai".

44 Podría aducirse asimismo Cat i ia2, si bien la autenticidad de la expresión "ho lógos tês ousías" que aparece allí ha sido puesta en duda desde la Antigüedad. 
suponer que el contenido de una "definición nominal" no ostente regularmente determinado contenido ontológico (aunque no existencial) ${ }^{45}$. Considérese el contraste entre, por ejemplo, la definición de "trueno (brontế)" y la definición del trueno: "sonido en las nubes" y "sonido en las nubes causado por la extinción del fuego". ${ }^{46}$ La fórmula "sonido en las nubes", a la vez que expresa lo que "trueno" significa, expresa, sin duda, lo que el trueno es, aunque no lo haga con la exhaustividad que requeriría la ciencia pertinente. Parece, pues, razonable entender que el saber acerca de las cosas encerrado en la competencia de los hablantes para aplicar las palabras apunta idealmente a lo que las cosas son en sentido estricto, y que contiene al menos un componente de lo que las cosas son ${ }^{47}$. En el texto de Met IV iv citado arriba Aristóteles podría haber tomado, en lugar de "hombre", un ejemplo como aquél, es decir, como "sonido en las nubes", que expresase el contenido de "trueno" sin indicación de la causa. Así vistas las cosas, la oposición entre la "definición nominal" y la "definición real”, que siempre se ha encontrado más bien problemática, se relativiza. Por cierto, sería muy difícil mantener la distinción en forma sistemática y rígida ${ }^{48}$.

\section{La condición inmediata de la significación}

Los desarrollos argumentativos expuestos en la Met a propósito del principio de contradicción permiten advertir, por otra parte, una condición de la que depende

\footnotetext{
45 No es claro cómo la definición pueda tener ya de por sí, según piensa Bolton (1976, p. 522), un contenido existencial, esto es, conllevar una cosa tal como la suposición o la creencia de que la cosa que se define existe, puesto que la definición de una cosa (o el concepto de una cosa) no parece poder contener la existencia de esa cosa como parte de su contenido, esto es, como rasgo o dato semántico. La creencia o la convicción de que la cosa existe (que es aquello a lo que Bolton se refiere) sólo podría consignarse, en todo caso, fuera o aparte de la definición misma, como algo accesorio y concerniente a las suposiciones del hablante que la formula, pero irrelevante para el contenido en sí de la definición o enteramente extrínseco a él. Como observa Coseriu (1975: 132), todo cuanto está en el dominio del sentido es algo pensado: la existencia no puede ingresar en la definición de nada.

${ }^{46}$ Cf. An Post II viii 93a21-24; II x; Met VIII iv 1044b12-13.

47 Bolton (1976, p. 516) señala incidentalmente que la definición nominal define la cosa tanto como la define la real, sólo que la define por medio de una formulación de lo que el nombre significa: una y otra forma de la definición no definen, por tanto, entidades distintas, sino la misma mediante formulaciones distintas (1976, p. 520).

${ }^{48}$ Cf. Deslauriers (1991, p. 16). En la realidad de la práctica usual de la definición lexicográfica la frontera entre los dos planos es transgredida constantemente o aun ignorada, como lo muestra la consulta de cualquier diccionario. Aun al modo de proceder de los teóricos en el terreno de la semántica se les ha objetado que al definir las palabras a cada paso abandonan, sin advertirlo, el plano metalingüístico y pasan al ontológico, porque definen las cosas más bien que las palabras.
} 
en forma directa o inmediata la comunicación lingüística entendida como intercambio de contenidos conceptuales o lingüísticos, a saber, la competencia de los hablantes para reconocer los referentes posibles de una palabra ${ }^{49}$. Pues como se ha dado a entender en el lugar de la Met citado más $\operatorname{arriba}^{50}$, cabe dar por sentada en todo hablante la aptitud para advertir la pertinencia de aplicar, por ejemplo, la denominación "hombre" a determinada cosa o realidad, lo cual implica, como es evidente, que se ha reconocido o se ha visto esa cosa como referente posible de "hombre", y se la ha identificado, por tanto, como un hombre. Aristóteles no señala de manera expresa a qué dominio remite esa capacidad de identificar así las cosas, pero parece claro que su raíz y, por tanto, la raíz de la aptitud para el uso lingüístico en general, está en el dominio de la experiencia (empeiría) $)^{51}$, es decir, en ese nivel prerreflexivo que, según Aristóteles, se sitúa entre el nivel de la percepción y la memoria y el nivel del arte (tékhne). La experiencia es la fuente de la familiaridad primaria y del trato primario que tenemos con las cosas, y es ella la que nos habilita para reconocer y decir que este $a$ que ahora se da aquí es un caso de " $a$ " o es un $a$ más, y ello, como se ha dicho, inmediatamente, es decir, sin mediación reflexiva o conceptual alguna: la captación o la identificación de la cosa pertenece al orden de la intuición (nóesis) ${ }^{52}$. Ahora bien, decir que en la mente de cada hablante particular se da un proceso inductivo de las notas distintivas (separadas de las notas accidentales) de cada especie de cosas, y que ese proceso precede al conocimiento de la palabra que denota la especie en cuestión, es, desde luego, formular una reconstrucción teórica

\footnotetext{
${ }^{49}$ Aparte de la que se señala arriba a continuación, hay una condición mediata que es la índole comunitaria de los hombres. Desde esta perspectiva la lengua no es sólo medio de comunicación de contenidos, sino factor que enlaza a los hombres entre sí en una comunidad, esto es, en una koinōnía, palabra que no ocurre en Met IV iv, pero sí en el texto paralelo de Met XI v (en el que se expone otra versión de las argumentaciones de Met IV iv), en el que se dice que entre los hombres se da una "comunidad discursiva mutua" ("koinōnía pròs allélous lógou", Met XI v 1062 a13; cf. toùs < ... > méllontas allélois lógous koinōnéseien, a11-12). En relación con el lenguaje (lógos) Aristóteles emplea "koinōnía" en Pol I x 1253a18, en el marco de la contraposición entre la comunicación animal y la humana: es la comunidad comunicativa, se dice allí, la que produce (poieî) la comunidad doméstica (oikían) y la comunidad política (pólin).

${ }^{50}$ Met IV iv 1006a32-34.

${ }^{51}$ Tratada por Aristóteles más escuetamente de lo que se desearía en An Post II xix y Met I i. Cf. Gregoric-Grgic (2006).

${ }^{52}$ El cual puede recaer tanto en lo que es objeto de la percepción intelectual cuanto en lo que es objeto de la percepción sensible, y es siempre, desde luego, una operación de la inteligencia intuitiva (noûs); cf. EN VI xi 1143b3-5.
} 
destinada a hacer comprensible el fenómeno. Pero parece natural suponer que ese proceso se da, más bien, con la adquisición del lenguaje o que es inseparable de ella, que es la que hace que nos instalemos en el mundo, puesto que, como parece claro, instalarse en un lenguaje es instalarse en un mundo ${ }^{53}$. Dicho de otra manera, el resultado, bajo la forma de un saber prerreflexivo, está ya contenido en el lenguaje que se adquiere, en el significado de cuyas unidades léxicas se ha sedimentado, como una variedad del éndoxon, el conocimiento que deriva del trato vivido con las cosas. Es, pues, allí, en el nivel de la experiencia (empeiría), donde están las raíces del saber lingüístico, el cual es, por otra parte, el presupuesto de toda actividad reflexiva, que es ya obra del entendimiento discursivo (diánoia), debiéndose incluir, por cierto, en esa actividad reflexiva la que se refiere al propio lenguaje, pues la reflexión metalingüística que resulta en la formulación de definiciones no parece ser, en lo esencial, sino el desarrollo o la explicitación discursivas de un saber previo que es el saber lingüístico prerreflexivo o que está contenido en él ${ }^{54}$. Ahora bien, es ése el plano en el que, como hemos sugerido más arriba, parece no poder escindirse la semántica de la ontología, esto es, donde parece no haber una frontera tajante entre saber a qué se llama "hombre" y qué es hombre. Tal saber, que concierne de ese modo tanto al sentido cuanto a la referencia, se resume y se expresa, como hemos dicho, en la capacidad de identificar de manera intuitiva y, por tanto, inmediata los referentes posibles de ésa y de toda otra palabra ${ }^{55}$. En otro lugar ${ }^{56}$ hace referencia Aristóteles al contenido de ese saber caracterizándolo como un todo (hólon) que se da a la percepción y es susceptible de una elaboración analítica (diaíresis) que diferencie en él las partes que se registran después en la definición (lógos) ${ }^{57}$. Es ése el modo en que en la competencia lingüística

\footnotetext{
${ }^{53}$ Cf. Gadamer (1967, p. 99).

54 Cf. Le Blond (1939, p. 354 y 361). Cabe notar que en terrenos tales como el de la ética, el establecimiento de lo que las cosas son toma la forma de una suerte de fenomenología de la semántica de las palabras que las denotan, y que en ese mismo terreno se suelen recoger distinciones ya consagradas en el léxico. Cf., por ejemplo, la distinción de las variedades de la mezquindad (aneleuthería) en EN IV i o de la irascibilidad en EN IV v, etcétera.

${ }^{55}$ A su manera, el señalamiento de este saber previo es respuesta a una paradoja de la especie de la del Menón platónico.

${ }^{56}$ Phys I i 184a24-26; b10-11.

${ }^{57}$ Cf. Wieland (1962, p. 93).
} 


\section{Eduardo Sinnott}

se contiene una comprensión precientífica global de las cosas que después la ciencia, que supone esa comprensión, toma como punto de partida, articula y completa.

4. Referencias bibliográficas

- Bolton, R. (1976). Essentialism and Semantic Theory in Aristotle. The Philosophical Review, (84), 514-544.

- Bonitz, H. (1848-1849). Aristotelis, Metaphysica. Recognovit et enarravit Hermannus Bonitz, Bonn.

- Coseriu, E. (1975). Die Geschichte der Sprachphilosophie von der Antike bis zum Gegenwart, I. Tübingen: Narr.

- Coseriu, E. (1979). tò hèn semaínein. Bedeutung und Bezeichnung bei Aristoteles. Zeitschrift für Phonetik, Sprachwissenschaft und Kommunikationsforschung, (32), 432-437.

- Deslauriers, M. (1991). Aristotle's four types of definition. Apeiron, (23), 1-26.

- Diès, A. (1950). Platon, Le Sophiste. Texte établi et traduit par Auguste Diès. París: Les Belles Lettres.

- Frege, G. (1975). Funktion, Begriff, Bedeutung. Göttingen: Vandenhoeck \& Ruprecht.

- Gadamer, H.G. (1967). Mensch und Sprache. Kleine Schriften. Tübingen: J.C.B. Mohr.

- Gregoric, P. - Grgic, F. (2006). Aristotle's Notion of Experience. Archiv für Geschichte der Philosophie, (88), 1-30.

- Haller, R. (1962). Untersuchungen zum Bedeutungsproblem in der antiken un mittelaterlichen Philosophie. Archiv für Begriffgeshcichte, (7), 57-75.

- Hamlyn, D. (1978). Focal Meaning. Proceedings of the Aristotelian Society, (78), 1-18.

- Hicks, R. D. (1965). Aristotle, De anima. Amsterdam: Hakkert.

- Hudry, J.-L. (2011). Aristotle on Meaning. Archiv für Geschichte der Philosophie, 93 (3), 255-280.

- Irwin, T. (1982). Aristotle's Concept of Signification. En: Schofield, M., Craven Nussbaum, M. (ed.) Language and Logos. Studies in Ancient Greek Philosophy Presented to G.E.L. Owen (pp. 241-266). Cambridge: Cambridge University Press.

- Jaeger, W. (1963). Aristotelis Metaphysica. Recognovit brevique adnotatione critica instruxit W. Jaeger, Oxford: Clarendon Press. 
- Kretzmann, N. (1974). Aristotle on Spoken Sounds Significant by Convention. En: Corcoran, J. (ed.), Ancient Logic and its Modern Interpretation. Dordrecht, Reidel.

- Le Blond, J. (1939). La définition chez Aristote. Gregorianum, XX, 351-380.

- Lieb, H. (1981). Das 'semiotishe Dreieck' bei Ogden und Richards: eine Neuformulierung des Zeichenmodells von Aristoteles. En: Weydt, H. (ed.) Logos semantikós. Studia linguistica in honorem Eugenio Coseriu, vol. II. Sprachtheorie und Sprachphilosopie. Berlín, Nueva York: de Gruyter.

- Minio Paluello, L. (1956). Aristotle, Categoriae et Liber de interpretatione. Recognovit brevique adnotatione instruxit L. MinioPaluello, Oxford: Clarendon Press.

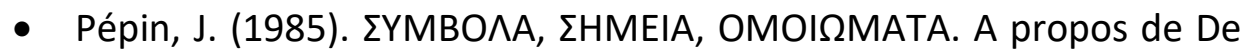
interpretatione 1, 16 a 3-8 et Politique VIII 5, 1340 a 6-39. En: Wiesner, J. (ed.) Aristoteles - Werk Und Wirkung, Bd I, Aristoteles Und Seine Schule. Berlin: De Gruyter.

- Polansky, R.; Kuczewski, M. (1990). Speech and Thought, Symbol and Likeness: Aristotle's De interpretation 16a3-9. Apeiron (30), 51-63.

- Schmitter, P. (1981), Zur Vorgeschichte der Kommunikationslehre. Zwei antike kommunikationsmodelle. Sprachwissenschaft, (6), 186199.

- Schmitter, P. (1987). Das sprachliche Zeichen. Studien zur Zeichenund Bedeutungstheorie in der griechiscen Antike sowie im 19. Und 20. Jahrhundert. Münster: Institut für Allgemeine Sprachwissenschaft der Westfalischen Wilhelms-Universität.

- Schmitter, P. (ed). (1991). Geschichte der Sprachtheorie. Tübingen: Narr.

- Sinnott, E. (2004). La elaboración del convencionalismo lingüístico en Platón. Stromata (60), 99-120.

- Sinnott, E. (2017). Acerca de las letras y los elementos fónicos en Aristóteles. Stromata, 73 (1), 31-56.

- Steintahl, H. (1969). Geschichte der Sprachwissenschaft bei den Griechen un den Römern mit besonderer Rüchsicht auf die Logik. Berlín: Dümmler.

- Weidemann, H. (1982). Ansätze zu einer semantischen Theorie bei Aristoteles, Zeitschrift für Semiotik, (4), 241-257. 
- Weidemann, H. (1991). Grundzüge der Aristotelischen Sprachtheorie. Schmitter, P. (1991). Sprachtheorien der abenländischen Antike, II. Tübingen: Narr.

- Wheeler, M. (1999). Semantics in Aristotle's Organon. Journal of History of Philosophy (37), 191-226.

- Wieland, W. (1962). Die aristotelische Physik. Göttingen: Vandenhoeck \& Ruprecht.

- Wyler, R. (1965). Der späte Platon. Hamburg: Meiner. 